\title{
MONEY AS STOCK: PRICE LEVEL DETERMINATION WITH NO MONEY DEMAND
}

\author{
John H. Cochrane
}

Working Paper 7498

http://www.nber.org/papers/w7498

\author{
NATIONAL BUREAU OF ECONOMIC RESEARCH \\ 1050 Massachusetts Avenue \\ Cambridge, MA 02138 \\ January 2000
}

This research is supported by the National Science Foundation via a grant administered by the NBER, and by the Graduate School of Business. New versions of this paper are maintained at http://wwwgsb.uchicago.edu/fac/john.cochrane/research/papers/. The views expressed herein are those of the author and not necessarily those of the National Bureau of Economic Research.

(C) 2000 by John H. Cochrane. All rights reserved. Short sections of text, not to exceed two paragraphs, may be quoted without explicit permission provided that full credit, including $\mathbb{C}$ notice, is given to the source. 
Money as Stock: Price Level Determination with no Money Demand

John H. Cochrane

NBER Working Paper No. 7498

January 2000

JEL No. F3

\section{ABSTRACT}

I show that a determinate, finite price level can be achieved in an economy with no monetary frictions, and no commodity standard or other explicit redemption commitment. I make one small modification to a standard cash in advance model: I reopen the security market at the end of the day. With this modification, overnight money demand is precisely zero. I show that the price level is still determined, however, by the government debt valuation equation.

Nominal government debt is, despite appearances, a residual claim to government surpluses. Thus, the price level is determined just like the price of stock, and just as if we used (say) Microsoft stock as numeraire, unit of account, and medium of exchange.

I resolve Buiter's (1999) criticism that fiscal price level determination mis-treats the government budget constraint. The government is not forced by a budget constraint to raise surpluses in response to an off-equilibrium deflation, just as Microsoft is not forced to raise earnings if there is a bubble in its stock price. I also address McCallum's (1998) criticism that fiscal models do not properly treat indeterminacies, and a number of other confusions and misconceptions surrounding fiscal price level determination. I provide a taxonomy of fiscal and monetary regimes.

John H. Cochrane

University of Chicago

1101 E. 58th St.

Chicago IL 60637

and NBER

john.cochrane@gsb.uchicago.edu

http://www-gsb.uchicago.edu/fac/john. cochrane/research/Papers/ 


\section{Introduction}

Suppose that Microsoft stock becomes numeraire, unit of account, and medium of exchange. When you buy coffee, you exchange a few fractions of a share, or a banknote, check or electronic transfer that promises such payment. Bonds promise future delivery of a share of Microsoft stock, rather than a dollar. Clearly, such a monetary system can establish a well-determined price level. We would understand that price level via the usual stock valuation equation,

$\frac{\text { number of shares }}{\text { price level }}=$ Expected present value of future dividends or earnings.

(The price level, shares per good, is the inverse of the share price, so it goes in the denominator.)

The fiscal theory of the price level recognizes that the monetary base, together with nominal debt, is a residual claimant to government surpluses, just as Microsoft stock is a residual claimant to Microsoft's earnings. If surpluses are not sufficient, the government must default on or inflate away the debt. Therefore, we can determine the price level via the valuation equation for government debt,

$$
\frac{\text { nominal government debt }}{\text { price level }}=\text { Expected present value of future surpluses. }
$$

An equivalent view is that money is valued because the government accepts it for tax payments. If the government requires money for tax payments at the end of a period, people will value money in trade during the period, even if there is no transactions-related friction. The government valuation equation (2) simply extends this idea to infinite period stochastic models. Starr (1974) presents the first formal analysis of a tax theory of value that I know of, though as usual one can find centuriesold verbal expressions of the ideas ${ }^{1}$.

${ }^{1}$ Starr (1974) quotes Kaulla (1934):

..the note debt of the state stands against a corresponding quantity of demands by the state which can be unconditionally satisfied by notes.

and Lerner (1948):

..if the state is willing to accept the proposed money in payment of taxes and other obligations to itself, the trick is done. Everyone who has obligations to the state will be willing to accept the pieces of paper with which he can settle the obligations, and all other people will be willing to accept these pieces of paper because the know that the taxpayers, etc., will be willing to accept them in turn."

Supreme court Chief Justice Salmon P. Chase, who had been Treasury Secretary during the Civil War, in a dissenting opinion on one of the "Legal Tender" cases, wrote a prescient description of the fiscal theory, including the relation of the price level to the "general credit of the country" (Chase 1870): 
Since Fisher (1911a,b, see especially the delightful artwork in 1911b) at least and perhaps since Hume's 1752 Of Money and Of Interest (see the quotations in Lucas 1996) almost all economic analysis of price level determination has relied instead on the quantity theory - a special demand for transactions-facilitating assets, combined with an artificially limited supply of such assets. It has also been understood for centuries that paper money can be valued with no transactions motive if it carries an explicit redemption promise as in the gold standard, commodity standards or a currency board. As the stock analogy and the tax story make clear, the fiscal theory can determine the price level with no money demand or other frictions, no restrictions on open market operations (the composition of nominal government debt across maturities or transactions-facilitating status), no restriction on private note issue, no restrictions on transactions technology or financial innovation, and no explicit redemption commitments. This fact makes the fiscal theory particularly attractive right now, as we live in an age of rapidly diminishing frictions and rampant financial innovation that undermine the foundations of the quantity theory (most recently, see Friedman 1999), yet roughly stable prices, and no hint of a commodity standard.

The main contribution of this paper is to demonstrate a determinate price level with no money demand, in the context of a fully-specified economic model. I modify a simple and standard cash in advance model by reopening the securities market at the end of the day. This modification allows consumers to hold no money overnight. Money demand is precisely zero, and velocity is infinite. Nonetheless, I show that this economy can have a determinate and finite price level.

I use this model because it is both a reasonable abstraction of the current U.S. payment system, and it maintains a close connection to the familiar cash in advance setup. Completely cashless economies (such as Sims 1997 and Cochrane 1999a,b) are analytically simpler, but conceptually more challenging. By maintaining the feature that transactions are still mediated by cash, even though no cash is held overnight, the nature of a nominal bond is clearer, inflation still feels like "too much money chasing too few goods," and it is clear how our current economy could be well approximated by this frictionless model.

Using this simple and familiar setup, I put to rest several persistent criticisms of the fiscal theory. Most importantly, the fiscal theory is often criticized (Buiter 1998, 1999; Bohn 1999) for apparently relying on a special ability of the government to violate or threaten to violate a budget constraint at off-equilibrium prices. I resolve

If the notes [greenbacks] would circulate as well without as with this quality [legal tender] it is idle to urge the plea of such necessity [legal tender laws]. But the circulation of the notes was amply provided for by making them receivable for all national taxes, all dues to the government, and all loans. ... Nobody could pay a tax, or any debt, or buy a bond without using these notes. ...The real support of note circulation not convertible on demand into coin, is receivability for debts due the government....It is plain that a currency so supported cannot depreciate more than the loans; in other words, below the general credit of the country.

I thank Ken Matheny for pointing me to these references. 
this long-standing confusion over the nature of the "government budget constraint."

Intuitively, the basic fiscal theory equation (2) is, like the stock example equation (1), a valuation equation, it is not a constraint. No budget constraint forces Microsoft (or Amazon.com!) to adjust future earnings to match current valuations. Microsoft can pay the dividends promised to equity holders for any market price. Analogously, no budget constraint forces the government to raise future taxes in response to an irrational or "off-equilibrium" deflation; it can keep its promises to debt holders no matter what the price level.

More deeply, the Government's decision of how much money and how many bonds to issue on each date are, like a corporation's decision of how many shares to issue in claim to a given earnings stream, decisions that define what securities are; they are definitions of units; definitions of which securities will be marketed. This definition occurs, for private and government issuers alike, before the auctioneer announces any prices, in any well-posed Walrasian model, and it occurs without constraint. We do not try to construct a supply curve in which you observe the price per share before you decide whether to issue 100 or 1000 shares, as you observe the price of tomatoes before deciding how many tomatoes to buy. If we did so, you would issue a lot of shares! Also, if Microsoft doubles the number of shares without changing the profit stream (a split), the price per share halves. If the government doubles nominal debt without changing the corresponding real surplus stream (a currency revaluation), the price level doubles. This is how a security definition works, as opposed to purchases of goods which have no effect on prices in competitive markets.

Of course, Government and private agents must obey budget constraints in buying or selling real debt, foreign debt, goods, and any already-defined securities, at equilibrium as well as off-equilibrium prices. This respect for budget constraints holds in the fiscal theory as in any well-defined equilibrium.

\section{$2 \quad$ Fiscal and quantity theories}

Despite their apparent differences, the fiscal theory, the quantity theory, and commodity standards are not mutually exclusive theories, but different cases of the same theory. Almost all monetary models include two equilibrium conditions which involve the price level, some variants of

$$
\begin{aligned}
M_{t} v & =p_{t} y \\
\frac{B_{t-1}}{p_{t}} & =E_{t} \sum_{j=0}^{\infty} m_{t, t+j} \tilde{s}_{t+j}
\end{aligned}
$$

where $M_{t}=$ nominal money, $y=$ income, $B_{t-1}=$ face value of one-period nominal bonds coming due at $t, m_{t, t+j}=$ stochastic discount factor, and $\tilde{s}_{t}=$ net of interest government surplus, including seignorage. The specific equations (3)-(4) result in the cash-in-advance model I present below. 
The first equation is a money demand function. Whether it is derived by currency in the utility function, a cash-in-advance constraint, a transactions technology or some other friction is not essential for this discussion. Velocity $v$ may depend on interest rates. This modification makes the solution more complex, since you have to find the entire price level sequence simultaneously rather than one point at a time, but does not change the basic points.

The second equation is often called, misleadingly I think, a "government budget constraint." I prefer and will use the term "government valuation equation." My central point is that this equation looks and acts just like the stock valuation equation (1). Long term debt complicates but does not essentially change the analysis (Cochrane 1999b, Woodford 1998b), again by forcing us to solve simultaneously for the entire sequence of prices.

The government determines debt, money and surplus, $\left\{B_{t}, M_{t}, \tilde{s}_{t}\right\}$. We see a problem immediately: (3) and (4) are two equations in one unknown, $p_{t}$. Therefore, fiscal $(B, \tilde{s})$ and monetary $(M)$ policies must be coordinated to determine a single price level, as Sargent (1987, p.168) emphasizes. Precisely, since any equilibrium requires both (3) and (4) to hold, equilibria only exist for a restricted set of $\left\{B_{t}, M_{t}, \tilde{s}_{t}\right\}$ processes.

It is useful, and a guide to the literature and history of thought, to specify some special cases, or regimes, that achieve this coordination. It is also useful to think of the Fed or monetary authority as having control of $\left\{M_{t}\right\}$ and of the treasury or fiscal authority as having control of $\left\{\tilde{s}_{t}, B_{t}\right\}$, and to describe regimes as the outcome of actions by the two parties. (Sargent 1987 describes this as a "game of chicken" between the Fed and Treasury. ) However, this story-telling can be deceptive. All that matters in the end is whether the government has produced a sequence $\left\{B_{t}, M_{t}, s_{t}\right\}$ that results in a unique, positive, price level sequence $\left\{p_{t}\right\}$ that simultaneously solves (3) an (4). There is nothing necessarily game-theoretic in the definition and characterization of equilibria.

1. Monetarist. The Fed determines $\left\{M_{t}\right\}$, and hence determines the price level $\left\{p_{t}\right\}$ with (3). The Treasury then adjusts surpluses; it chooses the sequence $\left\{\tilde{s}_{t}\right\}$ so that equation (4) holds at whatever price level emerges from (3) and the Fed's choice of $M_{t}$.

Most monetarist analyses start and stop at $M v=p y$ without presenting equation (4). This omission is sensible; the price level has already been determined and surpluses are only one of many less interesting endogenous variables. However, as foreseen by Friedman (1948) and emphasized by Sargent (1986), a complete quantity theory must include a fiscal valuation equation like (4) and a specification of fiscal policy that is consistent with monetary policy.

Explicit cash-in-advance models typically state that seignorage revenues are rebated to consumers by lump-sum transfers. (For example, see footnote 4 of Lucas and Stokey 1987, and a nice explicit treatment in Lucas 1984 p.36-37.) This is a simple 
example of a "passive" fiscal policy that makes equation (4) hold at any moneydetermined price level. The government makes seignorage revenue $\left(M_{t+1}-M_{t}\right) / p_{t}$, but gives it to consumers ("injects it"), which is an equal and opposite lump-sum transfer $s_{t}=-\left(M_{t+1}-M_{t}\right) / p_{t}$. In this way, the surplus including seignorage $\tilde{s}_{t}$ is zero at all dates, (4) reads $0 / p_{t}=0$ and thus holds for any money-determined price level.

2. Fiscal. The Treasury wins the game of Chicken. If the treasury fixes $\left\{\tilde{s}_{t}\right\}$ and $\left\{B_{t}\right\}$ then the government valuation equation (4) determines the price level. The Fed follows a "passive" policy, setting $M_{t}=p_{t} y / v$. The money demand equation now determines the quantity of money rather than determining the price level.

3. This paper. I show that there is a determinate price level even if there is no money demand; if $v=\infty$, or if we simply delete the money demand equation (3). Given $\left\{B_{t}, s_{t}\right\}$, the government valuation equation (4) can alone determine a positive the price level.

Most current fiscal theory research including Leeper (1991), Sims (1994), Woodford $(1994,1995,1996,1998)$, and Dupor (1999) studies economies in which there is a money demand and monetary friction. It rehabilitates money supply policies that are often thought to lead to an indeterminate price level, such as real-bills doctrines, interest rate pegs or providing "enough money to accommodate the needs of trade." It shows that such money supply policies are in fact consistent with a determinate price level so long as they are paired with an "active" fiscal regime - so long that the Treasury does not choose to alter surpluses systematically so that the government valuation equation (4) is satisfied for any price level.

I go one step further: the price level can be determined with no money demand either. Woodford (1998a,b) studies a cashless limit, and the price level is still affected by the Fed's interest rate policy. Here I study the limit point itself; the Fed is powerless to affect interest rates at this limit point.

Many names are used to distinguish the monetarist and fiscal regimes. Leeper (1991) distinguishes which of the Treasury or Fed is "active" and "passive," and I use this language. Woodford (1995) calls them "Ricardian" and "Non-Ricardian." Dotsey (1996) calls them "independent" and "dependent" monetary policy. Canzoneri, Cumby and Diba (1998) call them "Money-Determined" and "Fiscal-Determined."

Each of these labels has advantages and disadvantages. Neither the Fed nor Treasury need feel "passive," or that it has lost political power to the other. A Treasury that raises taxes in response to a rise in real debt may feel active and responsible, even if it is, in the end, raising taxes to finance a gift to bondholders engineered by a Fed-induced deflation. A Fed that follows an interest rate rule, real-bills doctrine, or "supplies enough liquidity to meet the needs of trade," may feel active and responsible, even though it is implicitly passing price-level determination on to the Treasury.

4. Unpleasant Monetarist Arithmetic. Sargent and Wallace (1981) study a fiscal 
regime in which the central bank still has some control over the path of inflation. Express the total surplus $\tilde{s}_{t}$ as its fiscal component (taxes minus spending, net of interest) $s_{t}$, plus seignorage. Then (4) becomes

$$
\frac{B_{t-1}}{p_{t}}=E_{t} \sum_{j=0}^{\infty} m_{t, t+j}\left[s_{t+j}+\frac{M_{t+j}-M_{t+j-1}}{p_{t+j}}\right]
$$

The above "fiscal" regime assumes that the treasury offsets any seignorage, thus controlling the full surplus $\tilde{s}_{t}$ independent of the Fed's actions, or (in practice) that seignorage is so small that it can be ignored. In Sargent and Wallace's fiscal regime, the Treasury controls primary surpluses, fixing $\left\{s_{t}\right\}$, but it does not control or offset the seignorage component of the surplus. Therefore, the Fed has some control over the price level path; it can choose "inflation now" or "inflation later" by its choice of $\left\{M_{t}\right\}$. If it chooses a low $M_{t}$ today, this will lower $p_{t}$ and raise the real value of the debt $B_{t-1} / p_{t}$. However, the Fed now must alone produce a coordinated policy; it must raise $\left\{M_{t+j}-M_{t+j-1}\right\}$ to raise seignorage at a future date so that (4) is satisfied at today's lower price level. This action must result in higher future inflation.

Burnside, Eichenbaum and Rebelo (1998) apply a similar model to the East Asian currency collapses from the summer of 1997. They show that currencies collapsed in, and only in, countries that had substantial bad news about future surpluses. They trace the results of doomed attempts at monetary stabilization in a model with interest elastic money demand as well as this seignorage channel.

The line between "monetarist" and "fiscal" regimes need not be sharply drawn. Many monetary analyses implicitly specify that in "normal times" the treasury will be passive, adjusting surpluses by small amounts to offset small changes in the value of the debt brought on by small changes in monetary policy; however, in extreme bad times, the fiscal requirements may become larger than the treasury can or will follow; then the fiscal regime becomes dominant and the currency must collapse or hyperinflate.

5. Fiscal rehabilitation of interest rate targets. Sims (1994) and Woodford (1999a,b) emphasize models in which the Fed follows nominal interest rate rules, as it currently appears to do. Nominal interest rate rules have also long been charged with leading to indeterminate price levels, but the fiscal anchor can lead to a determinate price level with such policies as well.

We can see this fact even in the simple setup of (3)-(4). Start with no uncertainty. If the Fed follows a nominal interest rate target, and if the real interest rate is fixed (say by linear utility or linear technology) at $r$, then an interest rate target means that the Fed follows whatever $\left\{M_{t}\right\}$ is required to generate a constant inflation rate $p_{t+1} / p_{t}=\pi$. For a given initial price level $p_{0}$, then, the Fed follows $M_{t}=y p_{0} \pi^{t} / v$ and we have $p_{t}=p_{0} \pi^{t}$.

If the Treasury is passive as in the monetarist tradition, this description of policy does not determine $p_{0}$, so the price level at each date is indeterminate. However, if the Treasury does not follow a passive policy, the initial price level can be pinned 
down by the government valuation equation (4), restoring price-level determinacy.

This example, while simple, can be confusing, since it suggests something different about the "initial period" and subsequent periods. This apparent difference is purely a result of a perfect foresight model. In a stochastic model, every day is an "initial period," so the entire price sequence is not pinned down by the nominal interest rate rule. Specifically, a nominal interest rate target is now an expected inflation target; the Fed sets $\left\{M_{t}\right\}$ to target $\pi=E_{t}\left(p_{t+1} / p_{t}\right)$. Money and prices follow random walks with drift, and $p_{t+1} / p_{t}=\pi+\varepsilon_{t+1}$. With a passive fiscal policy, this money supply regime does not determine the price level and money shocks $\varepsilon_{t+1}$ so the entire price level path is undetermined. An active fiscal policy and the government valuation equation (4) pins down the price level shock at each date.

6. Hyperinflation dynamics and indeterminacies. One theoretically interesting combination is a model with perfect foresight, the Fed sets money supply, and interestelastic money demand. For example, write a log-linear money demand function with velocity that increases with the nominal interest rate,

$$
M_{t} \bar{v}\left(p_{t+1} / p_{t}\right)^{b}=p y
$$

To keep the discussion as simple as possible, suppose money $M$ is constant. Then, (6) implies a difference equation for the price level,

$$
\ln p_{t+1}-\ln (M \bar{v} / y)=\frac{1+b}{b}\left[\ln p_{t}-\ln (M \bar{v} / y)\right]
$$

There is a family of solutions,

$$
\ln p_{t}-\ln (M \bar{v} / y)=\left(\frac{1+b}{b}\right)^{t}\left[\ln p_{0}-\ln (M \bar{v} / y)\right],
$$

indexed by the initial price level $p_{0}$. The price level is, again, indeterminate.

Many authors prune this indeterminacy by choosing the initial price level corresponding to the "minimum state variable" or "forward-looking" or "non-explosive" solution,

$$
\ln p_{0}=\ln (M \bar{v} / y) .
$$

However, this selection does not come from the model.

Woodford (1995) points out that an active fiscal policy can again determine the initial price level and hence determine the price level at any date. For example, if surpluses $s$ are also constant, the initial price level is the value $p_{0}$ that satisfies

$$
\frac{B_{-1}}{p_{0}}=\sum_{t=0}^{\infty} \frac{1}{r^{t}} s=\frac{r}{r-1} s .
$$

If $p_{0}>M \bar{v} / y$, this equilibrium will display an explosive price level, but an explosive nominal price level does not violate any equilibrium condition. If we do not see 
explosive prices, this means that governments do not pig-headedly follow policies such as this one (constant $M$, constant surplus) that give rise to explosive price levels.

McCallum (1998) (see also Kocherlakota and Phelan 1999) points out that Woodford's equilibrium cannot work if outstanding debt $B_{-1}$ is too low or surpluses are too high. Then, the initial price level is below the stable point, $p_{0}<M \bar{v} / y$; prices converge to zero; the real value of the money stock explodes; and the transversality condition is violated. McCallum suggests a mechanism that raises the surplus stream just enough to revive the $p_{0}=M \bar{v} / y$ equilibrium.

This point is valid and important to our understanding of the equilibria of this model. McCallum has found a restriction on the set $\left\{M_{t}, s_{t}, B_{t}\right\}$ of coordinated policies in this economy: we must have $B_{-1} / M \geq \frac{\bar{v}}{y} \frac{r}{r-1} s$. His repair is to increase surpluses; one could also increase government debt, by a helicopter drop or a 2 for one split, or return to a coordinated policy by many means.

However, this point is not a general criticism of the fiscal theory. We already know that not all specifications of government policy $\left\{M_{t}, s_{t}, B_{t}\right\}$ result in an equilibrium. It is not a requirement of a Walrasian equilibrium that one must exist for arbitrary policy specifications $\left\{M_{t}, s_{t}, B_{t}\right\}$, nor must a Walrasian equilibrium specify mechanism by which the government settles on a policy process that does produce an equilibrium. McCallum's restriction is true of monetarist as well as fiscal regimes.

Also, this model, involving perfect foresight, rigidly fixed $M$, completely exogenous $s$, and an interest-elastic money demand, is quite special. For example, the "fiscal" model above with an interest-inelastic money demand and the fiscal model I study below with no money demand do not display this price-level indeterminacy. Therefore, even a valid criticism of how the indeterminacy is resolved in this model does not tar the "fiscal theory" in general.

\section{Model}

I use a simplified version of the familiar cash-in-advance framework in Sargent's (1987) textbook. I derive equilibrium conditions similar to (3) and (4). I define the equilibrium, and I show by example that an equilibrium can exist in models with no money demand.

\section{Government choices}

The government chooses a path for one-period nominal debt, money and surpluses, $\left\{B_{t}^{s}, M_{t}^{s}, s_{t}\right\} . B_{t}^{s}, M_{t}^{s}, s_{t}$ are each random variables, and the notation $\left\{x_{t}\right\}$ denotes a sequence of random variables $x_{1}, x_{2}, \ldots x_{t}, \ldots$

There is no budget constraint that restricts the choice of $\left\{B_{t}^{s}, M_{t}^{s}, s_{t}\right\}$. As above, not all choices result in an equilibrium with positive and determinate price level, but budget constraints do not force the government to make choices that do lead to such 
an equilibrium.

\section{Household objectives}

Identical households maximize a standard utility function,

$$
\max E_{0} \sum_{t=0}^{\infty} \beta^{t} u\left(c_{t}\right)
$$

I assume $u^{\prime}(c)>0$ on $0 \leq c<\infty$ to ensure that budget constraints are not slack, and $u^{\prime \prime}(c)<0$ so that optimal choices are described by first order conditions.

\section{Timing and trade}

I consider two specifications of the trading mechanism: Sargent's cash-in-advance timing, and a frictionless variant. Figure 1 illustrates the timing of events in the cash-in-advance model, and Figure 2 illustrates the frictionless variant.

In both specifications, the representative household enters period $t$ with money balances $M_{t-1}$ and one period nominal discount bonds with face value $B_{t-1}$. Any news is revealed. The household then goes to the asset market. The household sells maturing bonds, pays net lump-sum taxes $p_{t} s_{t}$, buys new bonds $B_{t}$ and money $M_{t}^{d}$. Taxes must be paid in cash or maturing government bonds.

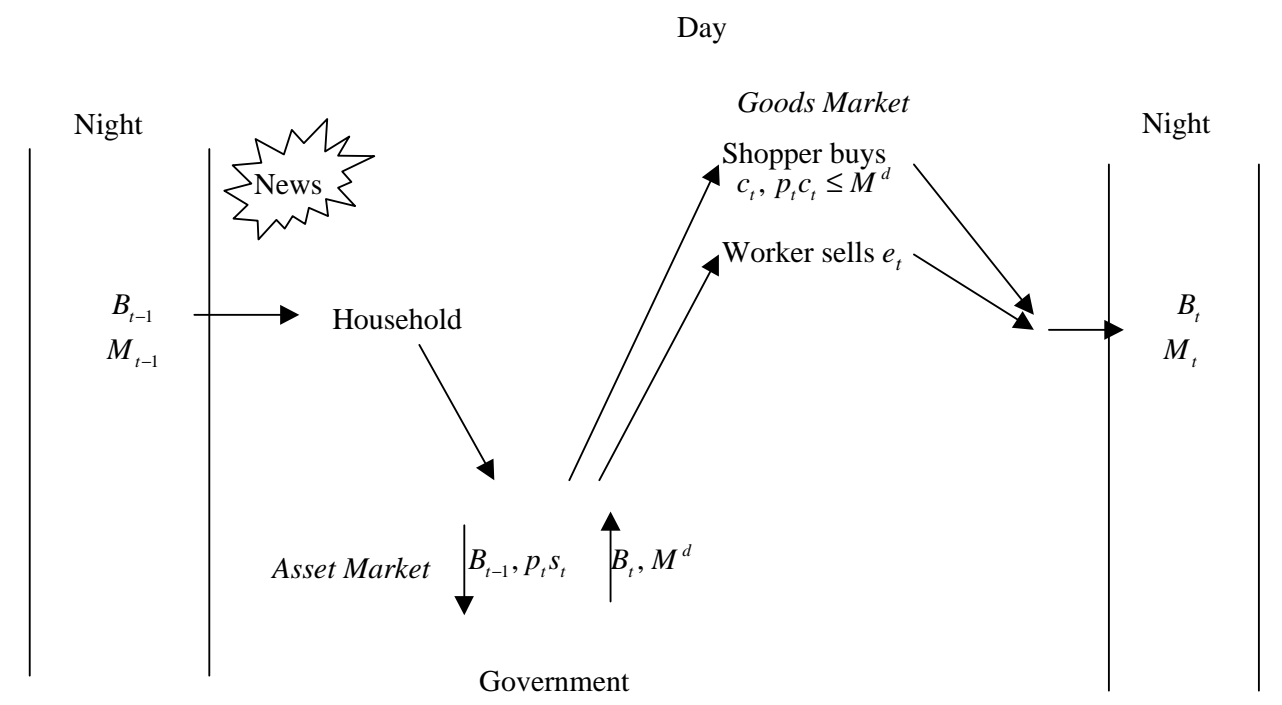

Figure 1: Timing of the cash-in-advance model.

Each household receives a nonstorable endowment $e_{t}$ in the goods market each day. The household cannot consume its own endowment, and must therefore buy the endowments of other households. To do this, the household splits up into a worker and a shopper. The shopper takes the money $M_{t}^{d}$ and buys goods $c_{t}$ subject to a cash in advance constraint,

$$
p_{t} c_{t} \leq M_{t}^{d} v
$$




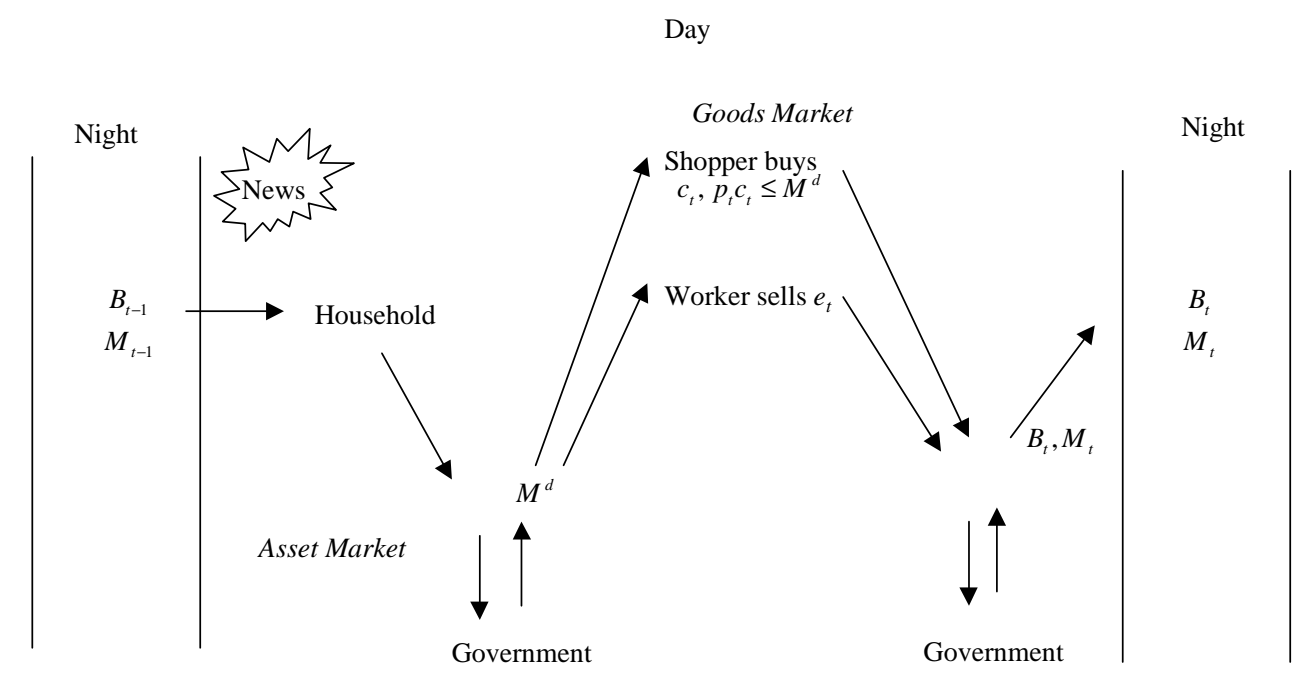

Figure 2: Timing in the frictionless model, with the security market open at the beginning and end of the day.

For the moment, $v=1$, but it is useful to introduce the parameter $v$ and consider what happens as it changes later. The worker sells the endowment $e_{t}$ in return for money, and gets cash in the quantity $p_{t} e_{t}$ in return.

Cash-in-advance model. In the cash-in-advance model, the shopper and worker go home and eat $c_{t}$. They must hold overnight any money $M_{t}^{d}-p_{t} c_{t}$ left over from the shopper, and the money $p_{t} e_{t}$ earned by the worker,

$$
M_{t}=M_{t}^{d}+p_{t}\left(e_{t}-c_{t}\right)
$$

They also hold any bonds $B_{t}$.

Frictionless model. The frictionless model makes one small change: The securities market reopens at the end of the day. There is no interest on intraday bond holdings or cash loans. (This is, roughly, the current institutional arrangement.) The household can return, and trade any unwanted cash for more bonds (or obtain new cash, if it wishes to). Thus, the household does not face the constraint (9); it can use cash during the day without holding it overnight. The absence of the constraint (9) is the only difference in the economic setup of the two models.

\section{Household budget constraints}

The household can trade arbitrary contingent claims in the asset market. I represent contingent claims prices by a real stochastic discount factor $m_{t, t+j}$. For example, the price of a 1 period nominal discount bond at time $t$ is

$$
Q_{t}=p_{t} E_{t}\left(m_{t, t+1} \frac{1}{p_{t+1}}\right)
$$


Discount factors chain together, $m_{0, t+j}=m_{0, t} m_{t, t+j}$ so once time-zero prices $\left\{m_{0, t}\right\}$ have been determined, the prices in markets that reopen at time $t$ follow. Since all households are identical, claims not provided by the government are in zero net supply and their presence or absence has no effect on the equilibrium prices or allocations. Therefore, I do not list such claims in the household budget constraints or the definition of equilibrium.

Households are forbidden to issue money, to keep them from arbitrageing zero interest money against interest bearing bonds,

$$
M_{t} \geq 0
$$

The household's period to period budget constraint states that the nominal value of money and bonds at the beginning of period, plus any profits in the goods market, must equal the nominal value of bonds purchased, money held overnight, and net tax payments,

$$
B_{t-1}+M_{t-1}+p_{t}\left(e_{t}-c_{t}\right)=Q_{t} B_{t}+M_{t}+p_{t} s_{t}
$$

As usual in infinite period models with dynamic trading, the household's debt demands $\left\{B_{t}\right\}$ must obey the transversality condition

$$
\lim _{T \rightarrow \infty} E_{t}\left(m_{t, T} \frac{B_{T-1}}{p_{T}}\right)=0
$$

in order to rule out rolling over debt forever.

\section{Definition of Equilibrium}

An equilibrium is a set of initial stocks $B_{0}, M_{0}$, and sequences for quantities $\left\{c_{t}, M_{t}^{d}, M_{t}, B_{t}, s_{t}\right\}$ and prices $\left\{m_{0, t}, p_{t}\right\}$ such that

1. (Household optimization) Given prices $\left\{p_{t}, m_{0, t}\right\}$, initial stocks $B_{0}, M_{0}$, and the tax and endowment streams $\left\{s_{t}, e_{t}\right\}$, the choices $\left\{B_{t}, M_{t}^{d}, M_{t}, c_{t}\right\}$ maximize expected utility subject to the budget constraints (12)-(13), the cash in advance constraint (8), and the no-printing-money constraint (11). In the cashin-advance model, the household must also meet the constraint (9) that money coming from the goods market must be held overnight.

2. (Market clearing) $c_{t}=e_{t}, M_{t}=M_{t}^{s}, B_{t}=B_{t}^{s}$ at each date and state of nature.

\section{Characterization of Equilibrium: CIA model}

The consumer's first order conditions, budget constraints, and market-clearing imply the following characterizations, familiar from Lucas (1984) and Sargent's (1987) text:

1. The marginal rate of substitution is equated to the stochastic discount factor,

$$
\beta^{j} \frac{u^{\prime}\left(e_{t+j}\right)}{u^{\prime}\left(e_{t}\right)}=m_{t, t+j} .
$$


Hence, nominal bond prices are given by

$$
Q_{t}=\beta E_{t}\left[\frac{u^{\prime}\left(e_{t+1}\right)}{u^{\prime}\left(e_{t}\right)} \frac{p_{t}}{p_{t+1}}\right]
$$

2. Any equilibrium with positive nominal interest rates $\left(Q_{t}<1\right)$, must have a binding cash constraint,

$$
M_{t} v=p_{t} c_{t}=p_{t} e
$$

3. The government debt valuation equation is

$$
\frac{B_{t-1}}{p_{t}}=\sum_{j=0}^{\infty} E_{t}\left[m_{t, t+j}\left(s_{t+j}+\frac{M_{t+j}-M_{t+j-1}}{p_{t}}\right)\right]
$$

or, equivalently,

$$
\frac{B_{t-1}+M_{t-1}}{p_{t}}=\sum E_{t}\left[m_{t, t+j}\left(s_{t+j}+\frac{r_{t+j}^{f}}{1+r_{t+j}^{f}} M_{t+j}\right)\right]
$$

where $r_{t}^{f}$ denotes the one period nominal interest rate,

$$
1+r_{t}^{f} \equiv 1 / Q_{t}
$$

Expression (17) counts seignorage revenue as it is made; expression (18) counts the interest differential between money and debt as the flow of seignorage.

Fact 1 follows from the household's first order conditions for buying one less consumption good, investing in a contingent claim, and then consuming more at $t+j$. Changing $c_{t}$ means that $M_{t}^{d}$ must also change, but cash overnight $M_{t}$ will be unaffected in the cash-in-advance model, because $p_{t} c_{t}$ changes by the same amount as $M_{t}^{d}$ changes (see equation (9)). Following Sargent (1987), there is no asset-pricing distortion with this timing convention.

With positive nominal interest rates, money is strictly dominated by bonds, so the household will hold as little as possible overnight. In the CIA model, that quantity is $M_{t}=p_{t} e$; goods market equilibrium gives $e=c_{t}$, and hence Fact 2 .

To derive Fact 3, use the bond price definition (10), iterate forward the consumer's period to period budget constraint (12), impose the condition (13), and impose market clearing $\left(e_{t}=c_{t}, M_{t}=M_{t}^{s}\right)$.

The pair (16) and (17) both determine the price level in terms of variables chosen by the government. Thus, as discussed in section 2 , an equilibrium only exists for a restricted set of $\left\{B_{t}, M_{t}, s_{t}\right\}$, i.e. if monetary and fiscal policies are "coordinated". Existence of equilibrium and the case of zero nominal interest rate are well treated by Lucas (1984) and Sargent (1987), so I won't delay getting to the point of this paper with a review. 
Characterization of Equilibrium: Frictionless model

1. The marginal rate of substitution (14) is still equal to the stochastic discount factor,

$$
\beta^{j} \frac{u^{\prime}\left(e_{t+j}\right)}{u^{\prime}\left(e_{t}\right)}=m_{t, t+j} .
$$

2. Any equilibrium with positive nominal interest rates $\left(Q_{t}<1\right)$, must have

$$
M_{t}=0 .
$$

No equilibrium may have negative nominal interest rates, $Q_{t}>1$.

3. The government debt valuation equation is

$$
\frac{B_{t-1}+M_{t-1}}{p_{t}}=\sum_{j=0}^{\infty} E_{t}\left(m_{t, t+j} s_{t+j}\right) .
$$

The flow budget constraint (12) is not changed, so first order condition behind fact 1 is the same.

Removing the constraint (9) that cash from sales must be held overnight, the minimum cash that the household can hold overnight is zero, so (20) replaces the quantity equation (16). Equation (20) is still a money demand equation, but it now holds for any price level and so does not help in price level determination. A negative nominal interest rate is an arbitrage opportunity, and leads to infinite money and negative infinite bond demand, and so cannot be an equilibrium.

Equation (21) specializes (18). In periods with positive nominal rates $r_{t+j}>0$, we have $M_{t+j}=0$, so the seignorage term drops because $M$ is missing. In periods with zero nominal rates, $r_{t+j}=0$, seignorage drops because there is no interest differential between money and bonds.

\section{Existence of Equilibrium}

There are specifications of the utility function, endowment processes, and government choices $\left\{B_{t}^{s}, M_{t}^{s}, s_{t}\right\}$ that result in equilibria of the frictionless model with determinate, finite price levels. I can prove this statement most transparently by giving the simplest example. Suppose $u(c)=c^{1-\gamma}, e_{t}=e, B_{t}^{s}=B, M_{t}^{s}=0, s_{t}=s$, all positive and constant over time. We can find prices and verify that this specification satisfies the definition of an equilibrium, by checking that it satisfies the first order and market clearing conditions that characterize that equilibrium. Obviously, we must have $c_{t}=e$. From (19), the discount factor is constant,

$$
m_{t, t+1}=\beta
$$

From (21), the price level must be constant and positive,

$$
p_{t}=p=(1-\beta) \frac{B}{s}
$$


Nominal interest rates are positive, $Q_{t}=\beta<1$ so money demand equals money supply $M=0 . \lim _{T \rightarrow \infty} \beta^{T} B / p=0$ so the transversality condition (13) is satisfied. The consumer's first order conditions and transversality conditions are necessary and sufficient for an optimum. Thus, we have found sequences $\left\{c_{t}, M_{t}^{d}, M_{t}, B_{t}, s_{t}, Q_{t}, p_{t}\right\}$ and $M_{0}, B_{0}$ that satisfy the definition of an equilibrium. Furthermore, given all the other variables, $\left\{p_{t}\right\}$ is unique. There is no indeterminacy or multiplicity of equilibria.

Not all specifications of the utility function, endowment process and government choices $\left\{s_{t}, B_{t}^{s}, M_{t}^{s}\right\}$ result in equilibria, as pathological utility functions and "uncoordinated" policy do not lead to equilibria in the cash in advance models. Here, I discuss the issues, but I do not attempt a characterization of the weakest possible restrictions on utility functions and exogenous processes that result in an equilibria.

As in all dynamic models, the endowment process and utility function must be such that equilibrium marginal rates of substitution $m_{t, t+j}=\beta^{j} u^{\prime}\left(e_{t+j}\right) / u^{\prime}\left(e_{t}\right)$ are defined and $E_{t}\left(m_{t, t+j}^{2}\right) \leq \infty$ so that asset prices are well defined (i.e. $m_{t, t+j} \in L^{2}$; see Hansen and Richard 1987.) For example, we can't have occasionally negative endowments and power utility.

Equation (21) and market clearing will ensure a unique, positive, equilibrium price level sequence $\left\{p_{t}\right\}$, if the government always chooses a positive amount of nominal debt at each date, $\infty>B_{t}^{s}+M_{t}^{s}>0$ and a surplus whose present value is positive $\infty>\sum_{j=0}^{\infty} E_{t}\left(m_{t, t+j} s_{t+j}\right)>0$. It is not necessary that all these sequences are positive. There can be equilibria with negative debt, surpluses or money supplies, but one must rule out $0 / 0=0$ problems in $(21)$.

One-period bond prices are determined from $Q_{t}=p_{t} E_{t}\left(m_{t, t+1} p_{t+1}\right)$. For there to be an equilibrium, the government must choose a price level sequence, via its choices of $\left\{B_{t}^{s}, M_{t}^{s}, s_{t}\right\}$, so that the expectation exists, and so that the nominal interest rate is nonnegative, $Q_{t} \geq 1$. If it chooses the price level sequence so that the nominal interest rate is positive, $Q_{t}>1$, then it must choose $M_{t}=0$. If it chooses the price level sequence so that the nominal interest rate is zero, $Q_{t}=1$, then any split between $M_{t}$ and $B_{t}$ is possible, since consumers regard money and bonds as perfect substitutes. If it chooses the price level sequence so that the nominal interest rate is negative, there can be no equilibrium. Households will try to hold infinite cash and infinite negative amounts of debt. Again, there are policies $\left\{B_{t}, M_{t}, s_{t}\right\}$ that result in equilibria, but not all policies do so.

\subsection{Generalizations of the frictionless model}

Long term debt.

One can allow more complex government finance, including long term bonds. This case is analyzed by Cochrane (1999b) and Woodford (1998b). This modification complicates the algebra and can fundamentally change the dynamic properties of the equilibrium, but does not alter the existence of equilibrium or the basic mechanism. 
A perpetuity is a simple and useful example long-term debt. Suppose that the government issues $D_{0}$ perpetuities at time 0 , and the perpetuities pay in aggregate a potentially state-contingent coupon $B_{t-1}$ at each date $t$. (I use the $t-1$ date in conformity with the other formulas.) Then, the price level at each date - dollars or coupon payments per good - is

$$
\frac{B_{t-1}}{p_{t}}=s_{t}
$$

The value of the perpetuities is

$$
\frac{D_{0} \times \text { time t perpetuity price }}{p_{t}}=E_{t} \sum_{j=0}^{\infty} m_{t, t+j} \frac{B_{t+j-1}}{p_{t+j}}=E_{t} \sum_{j=0}^{\infty} m_{t, t+j} s_{t+j}
$$

The price level is related directly to the coupon and surplus at each date, equation (22) rather than the present value equation (23) because the convention is that maturing debt, coupon payments or dollars are the numeraire rather than the perpetuities themselves. We could use 30 year treasury bonds or small denomination claims to such bonds as numeraire and medium of exchange. We happen not to do so. The volatility of long term bond prices makes this a wise, and perhaps not coincidental, choice.

\section{Less Cash}

The cash in advance constraint plays no essential role in the equilibrium. For any equilibrium of the frictionless model as stated so far, the same equilibrium (same sequences for $M_{t}, B_{t}, c_{t}, p_{t}$, etc.) holds if we halve or eliminate the cash constraint and halve or eliminate intraday cash $M^{d}$ at the same time. Equivalently, the parameter $v$ appears nowhere in the solution for the price level; we can choose $v=2$ or $v=\infty$. This fact has many interesting interpretations.

We can obviously let the security market be open constantly, and let all operations (debt purchases or sales, tax payments) happen at any time during the day.

We can allow private note issue. Formally, we can allow agents to sell claims to government debt, redeemable in the securities market, and allow those claims to be used to satisfy the cash in advance constraint in transactions. This is an important feature. In the quantity theory tradition, keeping a determinate price level has seemed to require rigorous control of private note issue, or private creation of transactions-facilitating assets that compete with government money. Checking accounts are controlled via reserve requirements, banknotes and small-denomination bearer bonds are forbidden. Of course we live in a time of great financial innovation, and only low inflation has kept the call for its the severe regulation in the name of price stability limited to academic circles.

We can also allow improvements in transactions technologies. Any amount of the goods can become "credit goods" or "credit card goods" whose purchase is paid for by agreements to exchange bonds in the asset markets. 
We can even consider a completely cashless economy, in which all transactions are made by (say) electronic transfer of private claims such as mutual fund shares. Maturing government bonds can be numeraire. Bonds can promise to pay "one dollar" even if no dollars are in circulation, because they can relieve the owner of one dollar's worth of tax liability. Whether the government gives you a dollar, and you hand the dollar back to pay taxes, or whether you simply surrender the maturing bond obviously does not change the equilibrium price level. The right to a dollar, even if never exercised in equilibrium, is valued. A completely cashless model is in fact a much simpler object to analyze, though the conceptual hurdles are larger for some. ${ }^{2}$

\section{Objections}

\subsection{Where is the government budget constraint?}

An unusual feature of this presentation is that there is no government budget constraint - no constraints on the government's choice of $\left\{B_{t}, M_{t}, s_{t}\right\}$. How have we achieved an equilibrium without imposing a constraint on government choices?

Related, critics including Buiter (1999) have charged that the government valuation equation (17) is a constraint. Hence, either the government must follow a passive fiscal policy so the fiscal regime equilibria are simply wrong, or the fiscal regime equilibria assume that the government is somehow different from private agents in that it can credibly threaten to violate a budget constraint at off-equilibrium prices.

The answer is simple, though subtle. There are three steps in defining a competitive Walrasian equilibrium: First, one defines what the securities are - what state-contingent stream of goods is promised for each share or unit of a security. Second, one finds demand and supply curves for those securities, as well as demand and supply curves for goods. Third, one finds find prices that clear markets. The decision of how much nominal debt and money to issue is a definition of securities. This action occurs without constraint, before the "auctioneer" announces any prices, for government and private issuers alike.

\section{Privately-issued equity}

We model privately-issued equity in competitive markets with this order of events. First, the issuer decides how many shares $B_{0}$ he will sell, pledging to divide the statecontingent profit stream $\left\{s_{t}\right\}$ evenly among the shareholders. (I am deliberately recycling the symbols with a different story.) He can sell as many or as few shares as he wishes; the $B_{0}$ decision defines the security. The equilibrium price $1 / p_{t}$ of the

\footnotetext{
${ }^{2}$ Buiter (1999) for example cannot digest the cashless model, and chastizes that "A theory that prices something which does not exist is quite an achievement. It should have rung alarm bells." It is, and it did, though bells of celebration rather than of alarm. At last, we have a coherent theory of money that does not rely on vanishing frictions or absent redemption commitments!
} 
securities at any date is then determined as

$$
\frac{B_{t-1}}{p_{t}}=\sum_{j=0}^{\infty} E_{t}\left(m_{t, t+j} s_{t+j}\right) .
$$

(Since the quantity outstanding does not change, $B_{0}=B_{t}$ at all dates for this security; I use $B_{t-1}$ for conformity with the other formulas).

Equation (24) is a supply = demand result, an equilibrium valuation equation (if $m$ denotes marginal utilities), or an arbitrage condition or a repackaging of ArrowDebreu securities (if $m$ denotes contingent claims prices). It is not a budget constraint. We would not imagine that the issuer can observe the share price $\left\{p_{t}\right\}$ before deciding how many shares to issue $B_{0}$, or before deciding how much to pay shareholders $\left\{s_{t}\right\}$ or other specifications of the security. If the issuer could see the share price before deciding on the number of shares, he would issue infinite quantities! Mistaking the definition of a security for the purchase or sale of a good or a defined security introduces an arbitrage opportunity into the model, and no equilibrium can exist with this mistaken specification.

In sum, when we write a competitive equilibrium model with private equity, we start by specifying that each issuer determines a number of shares and the statecontingent dividend stream, $\left\{B_{0}, s_{t}\right\}$. There is no constraint on this choice - agents can arbitrarily bundle and sell contingent claims. The specification of "government choices" above is exactly analogous.

Nominal government debt is a residual claim to surpluses

One might object that this is fine for equity - a security whose stated promise is to divide the random surplus stream $\left\{s_{t}\right\}$ - but government debt is debt. In fact, however, nominal government debt is really a residual claim to surpluses. It walks like debt, it quacks like debt, but it is really equity.

The stated promise of nominal government debt is to "pay one dollar." However, it also comes with the promise that "a dollar can be used to pay taxes," and "a dollar can be used to buy new bonds." Together, these three promises mean that nominal debt is, in an accounting sense, exactly the same as a promise to split up the state-contingent stream of real government surpluses among bond-holders.

Since a dollar can always be used to discharge one dollar's worth of tax liabilities, a bond holder can trade a dollar to another consumer, in return for goods corresponding to one dollar's worth of tax liabilities. How many goods is that? In a last period, or if no new government debt is sold $\left(B_{t}=0\right)$, the aggregate value of nominal debt must be equal to the aggregate value of net tax payments,

$$
\frac{B_{t-1}}{p_{t}}=s_{t} .
$$

To a bond-holder, then, the payoff to bonds are exactly as if the government took goods $s_{t}$ from taxpayers and split them up among the bond-holders - as if nominal government debt were, explicitly, equity. 
If the government sells some new debt, $B_{t}>0$, in a multiperiod model, then a bond holder can also use a dollar to purchase a new bond. In aggregate the value of outstanding government bonds is now given by

$$
\frac{B_{t-1}}{p_{t}}=s_{t}+E_{t}\left(m_{t, t+1} \frac{B_{t}}{p_{t+1}}\right) .
$$

To a bond-holder, then, the payoffs of nominal one period government bonds are exactly the same as those of an explicit promise to split up the stream $\left\{s_{t}\right\}$ proportionally among the bond holders.

One-period government debt is rolled over every period while private equity is an infinite period security. This difference is also not essential. Private agents can issue equity that is rolled over every period, and this security acts exactly like one period nominal government debt. At each date, the issuer promises to redeem the previous period's equity, devoting the current earnings $s_{t}$ and the proceeds from a new issue to the task. Conversely, as described in section 3.1, governments can issue long-term debt (perpetuities) that looks just like the infinitely-lived private equity described above.

How can the government issue more debt without increasing surpluses?

We usually think that when the government issues more debt, it must, by budget constraint logic, increase the future stream of surpluses that will retire that debt. By writing the government's choices without constraint, we deny this statement. How can the government issue more debt without increasing future surpluses?

A corporation may double its shares without changing future earnings, and this action simply halves the equilibrium price. A stock split is a practical example. The corporation knows this in contemplating a stock split; it does not think it has to double earnings and take the price per share as given. Analogously, the government may double its nominal debt without changing future real surpluses. A currency revaluation is a practical example. This action doubles the price level, and the government knows this in contemplating such an action. It does not have to take the price level as given, and thus it does not have to double surpluses.

Governments choose to pair the vast majority of nominal debt issues with implicit or explicit promises to raise future surpluses. Governments typically issue nominal debt to finance wars or countercyclical spending; they want to raise revenue by these issues and they do not want to raise the price level. If they issue debt without changes in future surpluses, they raise prices and not revenue. Thus most of our experience and the bulk of time series variation consists of debt changes that are paired with changes in future surpluses. But currency revaluations are possible, even if infrequent. Must the government react to off-equilibrium prices?

Suppose that the Walrasian auctioneer announces an off-equilibrium price. Conventional demand curves must respect budget constraints even at off-equilibrium prices. Yet at off equilibrium prices, the government valuation equation fails to hold. 
Must the government, by budget constraint logic, adjust the stream of future surpluses in response to an off-equilibrium price level?

The answer is no. Again, it helps to start by analogy with private equity. Once the equity is issued, the firm only has to pay off the sequence $\left\{s_{t}\right\}$ to equity holders, as promised. The firm may, by budget constraint logic, completely ignore the price of its stock.

Most simply, if I have issued a security that reads "John Cochrane will provide the bearer one referee report" I can meet the contractual and budget constraint requirements of that security while completely ignoring the evolution of its secondary market price. If the security trades for two referee reports that does not mean $I$ must provide two reports on demand; if it trades for $1 / 2$ report, I must still provide the full report to someone who presents it to me.

The same is true for nominal government debt. Once the government has announced the state-contingent sequence $\left\{B_{t}, M_{t}, s_{t}\right\}$ it may, by budget constraint logic, completely ignore the price level. (It may not choose to do so, which is why I keep highlighting the may in these sentences, but the argument is about what it must do.) The government must honor the terms of the security: it must exchange one dollar for each maturing bond, it must accept one dollar in exchange for one dollar's worth of tax liability, and it must auction new debt for dollars and accept dollars in exchange for new debt. It can honor these commitments at arbitrary off-equilibrium prices.

Of course, markets will not clear at off-equilibrium prices: there will either be too many or too few dollars around relative to tax liabilities. But this is precisely the point: the government valuation equation comes from market clearing, not a budget constraint. Market clearing conditions obviously do not have to hold at off-equilibrium prices.

\section{Real debt}

The government does face budget constraints in other transactions, just as private agents do. There is no government budget constraint in the model I have written down only because I left out of the model any role for the government other than defining the units of government debt and money, and collecting lump-sum taxes by retiring maturing debt or money. If the government wants to buy or sell goods and services, foreign debt, indexed debt, real debt, or other already-defined bundles of contingent claims; if the price level is defined in terms of gold or foreign currency, or if it wants to engage in any other transaction, it must obey the relevant budget constraint, at off-equilibrium as well as equilibrium prices.

For example, suppose that the government issues real rather than nominal debt: either goods are numeraire, so $p_{t}=1$ by definition, or foreign currency is numeraire so $p_{t}$ is exogenous to the economy. A bond is now a completely state-uncontingent promise to pay one unit of the numeraire good. Then the government valuation 
equation

$$
\frac{B_{t-1}}{p_{t}}=E_{t} \sum_{j=0}^{\infty} m_{t, t+j} s_{t+j}
$$

does act as a constraint. The government's choices of $\left\{B_{t}, s_{t}\right\}$ must obey (25), an increase in $B_{t}$ must come with increases in subsequent $\left\{s_{t+j}\right\}$, and the government must adjust future surpluses $\left\{s_{t+j}\right\}$ if changes in $p_{t}$ - "on equilibrium" or "off-equilibrium" change the value of its debt.

It may be more productive to look at this case as a mismatch between assets and liabilities rather than as a budget constraint. The asset - the stream of surpluses is random, but the liability - real debt - is completely un-contingent. There is no residual claimant, or other equity-like asset to soak up the difference. Thus, the asset stream $\left\{s_{t}\right\}$ must be transformed so that it, too is not state-dependent.

In the case of gold or foreign currency as numeraire, there is an extra twist: the real amount to be paid depends on the price level $p_{t}$. A promise to pay numeraire is a larger commitment if the price level is lower than if it is higher; and this commitment (like all specifications of securities) must be enforced at off-equilibrium as well as onequilibrium prices. Thus, the government must respond to an off-equilibrium price by raising the real surplus used to pay off debt holders.

Again, there is no difference between government and private agents. A government that issues real debt is exactly like a firm that issues only real debt and no equity. The owners of such a firm hold all the risk, they must come up with additional funds if the firm's earnings are not sufficient to cover the real debt payments; they must transform the initially state-contingent earnings stream into a non statecontingent stream of payments to bond holders. If a firm issues debt denominated in a numeraire, then the firm's owners additionally take on inflation risk: if $p_{t}$ declines so that the firm's debt becomes more valuable, the firm must raise future resources to pay off the higher value of its debt, in order to honor the terms of its debt contract. There is a good reason that firms issue equity, and governments issue nominal debt!

\section{Defaultable debt and equity}

Of course, the government or a debt-only firm might also default. Defaultable debt is a different and state-contingent security in Arrow-Debreu markets. If the price level declines, the probability of explicit default can now rise, so the government no longer must raise future surpluses. It is still true that the nominal value of government debt divided by the price level equals the present value of future surpluses, and this equation determines the price level. However, changing probabilities of default, and hence changing relative values of different maturities of debt can now soak up surplus shocks in place of the price level.

For example, suppose that the government issues an indexed but state-contingent perpetuity. Though the perpetuity carries a stated promise to pay the dollar value of one good each period, in fact the government will pay less if surpluses are insufficient and more if surpluses are abundant. Let $d_{t}$ denote the number of dollars actually 
paid per dollar promised at time t. Then, the price level at each date $t$ is determined by

$$
\frac{B_{t-1} d_{t}}{p_{t}}=s_{t}
$$

If the government makes all adjustments by state-contingent default, paying $d_{t}=$ $s_{t} / B_{t-1}$ cents on the dollar, the price level is determined by this fiscal regime and is constant! The relative price of perpetuities rather than the price level soaks up all the shocks to government surpluses.

In this example, "defaultable debt" has become equity. This example shows that the invention of true equity-like securities - securities whose relative prices can soak up stochastic variation in government surpluses - might be very beneficial. Explicit default and inflation are costly, and an explicit equity-like security would allow statecontingent government finance without those costs. However, the difference between bad luck and bad management in determining $s_{t}$ is not so easy to see, which is why private equity comes with control rights; what takes the place of control rights is the central question for the invention of public equity.

\section{A stylized history}

The transition from commodity money or gold standard to a monetarist regime to a fiscal regime provides a nice stylized history. Under the gold standard, the treasury really did have to follow a "passive" regime. If the price level declined, it had to increase surpluses to avoid default. In a monetarist regime, the treasury continued to act "passively," as if the economy were still on a gold standard. As the central bank moves to money supply policies - passive money, interest rate pegs - that, alone, lead to an unstable price level, the treasury can quietly and subtly move to an "active" regime which does stabilize the price level. It would be easy for observers and the treasury itself not to notice the difference. In equilibrium, the joint process of money, bonds, and surplus can be exactly the same in all three regimes. The treasury can continue to act exactly as it always has.

\subsection{Transversality condition}

\section{What is the transversality condition?}

The transversality condition is a source of endless confusion in the fiscal theory debates. In this complete-markets model, the transversality condition, equation (13) is a limitation on dynamic trading schemes in markets that are reopened each day, so that the budget set achieved by dynamic trading is no different than that achievable by trading in time-zero contingent claims. Equivalently, it rules out arbitrage opportunities between multiperiod securities and dynamic trading strategies in the sequence of markets. In a complete markets model, a violated transversality condition does not just imply that debt grows fast; it implies that you can make money

and enjoy a free lunch right away. (Continuous-time models also feature additional 
restrictions that trades cannot be "too fast" in order to prevent agents from creating arbitrage opportunities by dynamic trading. See Duffie 1992 p.78. ).

The transversality condition for government debt is a component of the household budget constraint. It is not a component of a government budget constraint, since the government defines the nominal debt security. The government must obey transversality conditions, as it must obey budget constraints, if it purchases or sells real debt or other already-defined securities.

These points are easier to see by writing out a large set of conventional, real, long-lived securities rather than in the special case of one-period nominal government debt. Suppose that there is a vector of securities traded at time $t$, which pays a vector of dividends $\left\{\mathbf{d}_{t}\right\}$, with price $\left\{\mathbf{P}_{t}\right\}$, and a full set of contingent claims with prices (scaled by probabilities) $m_{t, t+j}$ are also traded. By the law of one price, the securities must have the same value as their contingent-claim counterparts,

$$
\mathbf{P}_{t}=E_{t} \sum_{j=1}^{\infty} m_{t, t+j} \mathbf{d}_{t+j}
$$

If the consumer wakes up at time $t$ with asset holdings $\mathbf{X}_{t-1}$ of these securities, sells them all, and purchases contingent claims for future consumption, the budget constraint on his consumption stream $\left\{c_{t}\right\}$ is

$$
\mathbf{X}_{t-1}^{\prime}\left(\mathbf{P}_{t}+\mathbf{d}_{t}\right)=E_{t} \sum_{j=0}^{\infty} m_{t, t+j} c_{t+j}
$$

If instead the consumer trades dynamically in the sequence of spot markets, his period-to-period constraint says that asset purchases or sales plus dividends equals consumption,

$$
\left(\mathbf{X}_{t-1}-\mathbf{X}_{t}\right)^{\prime} \mathbf{P}_{t}+\mathbf{X}_{t-1}^{\prime} \mathbf{d}_{t}=c_{t}
$$

Using this equation at $t+1$, multiplying by $m_{t, t+1}$, taking expectations, and substituting the result for $\mathbf{X}_{t}^{\prime} \mathbf{P}_{t}$ yields

$$
\mathbf{X}_{t-1}^{\prime}\left(\mathbf{P}_{t}+\mathbf{d}_{t}\right)-E_{t}\left(m_{t, t+1} \mathbf{X}_{t+1}^{\prime} \mathbf{P}_{t+1}\right)=c_{t}+E_{t}\left(m_{t, t+1} c_{t+1}\right)
$$

Continuing in this way, dynamic trading implies the following constraint on the consumption stream:

$$
\mathbf{X}_{t-1}^{\prime}\left(\mathbf{P}_{t}+\mathbf{d}_{t}\right)-\lim _{T \rightarrow \infty} E_{t}\left(m_{t, t+T} \mathbf{X}_{t+T}^{\prime} \mathbf{P}_{t+T}\right)=E_{t} \sum_{j=0}^{\infty} m_{t, t+j} c_{t+j}
$$

Comparing (26) and (27), we can see that, if the sequence of trades $\left\{\mathbf{X}_{t}\right\}$ is not constrained to satisfy

$$
\lim _{T \rightarrow \infty} E_{t}\left(m_{t, t+T} \mathbf{X}_{t+T}^{\prime} \mathbf{P}_{t+T}\right)=0
$$

then the set of consumptions $\left\{c_{t}\right\}$ available from dynamic trading is larger than that available from time zero contingent claims. 
If the condition (28) does not hold, there is an arbitrage opportunity (precisely, a violation of the law of one price). The consumer can sell a security, eat the proceeds at time $t$, and then cover the promised dividends by ever-increasing sales of additional securities. The profit is instantaneous.

The condition (28) can be implemented by positive marginal utility and a borrowing constraint on total wealth, $\mathbf{X}_{t}^{\prime} \mathbf{P}_{t}>-W_{t}$, where $W_{t}$ grows slowly enough, as explained in the fiscal theory context in Woodford (1995). Woodford also suggests the contingent claim value of the endowment as a useful value of this constraint, since that is the most the household could ever hope to repay.

In our model, the real value of debt is $B_{t-1} / p_{t}$. Thus, the condition $(28)$ is as given by (13) above, namely

$$
\lim _{T \rightarrow \infty} E_{t}\left(m_{t, T} \frac{B_{T-1}}{p_{T}}\right)=0
$$

where $B$ refers to the household's demand for nominal debt.

This constraint does not apply to or restrict the government, as explained above. If the government doubles its supply of nominal debt, the price level also doubles.

\section{Explosive debt problems for the fiscal theory}

Take a perfect-foresight version of the model with a constant interest rate $r$. The one period valuation equation is

$$
\frac{B_{t-1}}{p_{t}}=s_{t}+\frac{1}{r} \frac{B_{t}}{p_{t+1}}
$$

What happens if this one-period valuation equation (relating $p_{t}$ to $p_{t+1}$ ) holds correctly, but the overall level is too high or too low? The answer is, solving (30) for the last term and iterating forward, that the real value of debt grows explosively, violating the transversality condition.

Can the government threaten to let real debt explode at off-equilibrium paths? The answer is, yes; this does not violate a government budget constraint. This is just one special case of an off-equilibrium price, and, as discussed above, the government can completely ignore the price level if it chooses to do so, just as private issuers can ignore the secondary market value of their stock.

Will the government ignore off-equilibrium prices? For example, McCallum (1998) worries that declining real values of debt will lead the government to reduce surpluses, or that rising market values of debt will lead them to raise surpluses. This is a valid concern, but not one that makes much sense in a Walrasian specification. Walrasian equilibrium describes only the equilibrium; we never see "off equilibrium" behavior for a period, let alone for a long stretch of time for which the government's resolve can be tested; we do not observe an adjustment process toward equilibrium. And "off equilibrium" economies are weird in lots of ways, since markets don't clear and commitments underlying budget constraints cannot be fulfilled. In the complete-markets 
economy I have described, for example, the government's reaction to slowly growing debt is a secondary concern: any "off equilibrium" price level is an arbitrage opportunity, which leads to immediate and infinite positive or negative private demand for government debt.

\subsection{Rational Expectations}

I have described a time-zero, competitive, contingent-claim, Arrow-Debreu equilibrium. Information is symmetric and is generated in the standard way. Thus, sequences such as $\left\{B_{t}^{s}\right\}$ are sequences of random variables, functions from a state space $\Omega$ to the real line, in which each element $B_{t}^{s}(\omega)$ is measurable with respect to the common (to households and government) time- $t$ information set. The government announces the sequences $\left\{B_{t}^{s}, M_{t}^{s}, s_{t}\right\}$, i.e. how each decision will be taken contingent on time-t information, agents then announce demand curves for state-contingent consumption and asset demands, and equilibrium asset prices are determined.

A rational expectations equilibrium is more realistic than time-zero "announcements" and time-zero contingent claim equilibrium. In a rational expectations equilibrium, agents learn the government's policy process over time. For this specification it is important to impose that random variables are stationary, so that agents can learn their distributions - the state-contingent choices of $\left\{B_{t}^{s}, M_{t}^{s}, s_{t}\right\}$ - by observing long enough histories. For example, following Lucas (1984) we can specify that information is generated by an $N$-dimensional vector of random variables $S_{t}$ that follows a Markov process, and then impose the more stringent requirement that all sequences are time-invariant functions $B_{t}^{s}\left(S_{t}\right)$.

In either rational expectations or time-zero contingent claim equilibria, we must remember that the equilibrium involves entire sequences or processes, since expectations of future policies matter centrally. For example, Bohn (1999) states that "the notion that bondholders are residual claimants on the government is a dangerous and misguided idea," asking, "why should we advise politicians to maintain stable prices? Why should we expect a politician ever to enact a budget surplus?" and "it is unclear how and by whom these 'promises' [that surpluses will pay off current debt] are made and how they are enforced." The answer to all these questions, of course, is that policy is a process, not a sequence of decisions made in isolation.

\section{Concluding Remarks}

\section{Time-Consistency and game theory}

The main point of this paper is to show that fiscal price level determination can work, in a completely specified Walrasian economy, even if money demand falls to zero. Many criticisms of the fiscal theory are in fact criticisms that Walrasian 
equilibrium is an inappropriate solution concept, not that the fiscal theory applies it incorrectly. Other equilibrium concepts may be important in the fiscal theory as in dynamic public finance more generally.

Of course, time-consistency is a potentially important issue in any dynamic theory of government policy. Especially with long-term debt, the government can lower inflation by a surprise devaluation (see Cochrane 1999b for an analysis in this kind of model). However, if everyone expects a surprise devaluation, it won't be a surprise anymore and won't lower inflation.

In the model of this paper, there is no time-consistency problem, since I have given the government no objective, and it is a Walrasian model that presumes costless contract enforcement. In general, time-consistency, like other options to abandon contracts, amounts to a further restriction on the set of equilibria. On the other hand, time-consistency problems lead to the search for commitment and reputation mechanisms by which one can restore the full-commitment set of equilibria. The time-consistency is analogous to the problem that private stock issuers are tempted not to deliver the promised stream $\left\{s_{t}\right\}$. Private equity must surmount agency costs, dilution, mis-reporting of the random earnings, and so forth. The fact that government debt has evolved from real debt with frequent default, to real debt closely monitored by a few large banks (Sargent and Velde 1995), to nominal debt which does not explicitly default but gets inflated away, dragging private nominally-denominated contracts with it, suggests an evolution of monitoring institutions.

More generally, we have seen that the fiscal theory does rely on commitments by the government to follow policies at off-equilibrium prices that may be possible, but might not be credible. The process of adjustment to, or adoption of a consistent policy regime is also interesting. This suggests interesting game-theoretic solution concepts in place of Walrasian equilibrium. However, the fact that private equity works-and does work-exactly the same way, suggests that such an investigation will lead to a deeper understanding of how it works rather than to a proof that it cannot work.

\section{Frictions}

I have focused on a frictionless economy. This is a sensible first step. Including frictions obscures the fact that the price level can be determined (and maybe is) without reference to any frictions or money demand at all. Also, for many issues, monetary frictions may only have minor, second order effects. In such cases, it makes sense to first understand the basic issues with no frictions, and add the frictions later.

Sometimes, second-order liquidity issues are important, and models with frictions are appropriate for those cases. As I discussed above, any model that wants to capture some remaining ability of the Federal reserve to run an interest rate policy must include some frictions. As another example, suppose that there is news that future surpluses are going to be really bad - as undoubtedly happened in Russia in the summer of 1998, and arguably (Burnside, Eichenbaum and Rebelo 1998) in East 
Asia in 1997. A frictionless analysis with one-period debt suggests that the exchange rate must decline immediately - $B_{t-1}$ is fixed, so if $E_{t} \sum_{j=0}^{\infty} m_{t, t+j} s_{t+j}$ declines, $p_{t}$ must rise. This is a good place to start. In a monetarist regime, open market operations can peg the exchange rate at any level. The fiscal analysis reminds us that open market operations cannot postpone the inevitable collapse forever. However, central banks can postpone the moment of reckoning for a few days or even weeks by increasingly desperate open market operations. A fiscal model with money can capture this fact, and describe the options that central banks have to manage the minutiae of the crisis.

\section{Empirical implications}

Again, the "regimes" are just stylized mechanisms that the government may follow to attain a coordinated monetary and fiscal policy. Given a coordinated policy, the internal workings and who controls what does not matter to the equilibrium. Alas, however, this fact means that there will be no clean test for a fiscal vs. a monetarist regime. The pure difference between regimes has no observable implications for the time series of $\left\{M_{t}, B_{t}, s_{t}, p_{t}\right\}$; any "coordinated" policy achieved by one regime could have been achieved by another regime as well.

We can judge whether a given set of time series is more plausibly generated by one regime or another. This is not an unusual or hopeless circumstance. For example, monetary aggregate rules and interest rate rules are indistinguishable in the same way, since a constant interest rate could happen to be the result of a sufficiently state-dependent monetary aggregate rule. We are all comfortable ignoring this observational equivalence and thinking of stable interest rates with fluctuating aggregates as an interest rate targeting regime.

The difference between regimes may be most useful if it allows us to make some sense of why governments choose the policy paths that they do. For example, interpreting a currency collapse as the result of intractable fiscal problems makes it more understandable than having to rely on the stupidity or spinelessness of central bankers unwilling to conduct requisite open market operations. Daniel (1999) follows this path. Similarly, inflationary episodes such as the 1970s in the US are typically interpreted as mistakes of the Fed policy rule. They would be much more understandable as optimal state-contingent defaults. Reaching such an understanding requires a model of optimal distortionary taxation rather than the lump-sum specification of this paper.

Changing the specification of the model, such as dropping the money demand function, does have empirical implications. The fiscal theory may ultimately be interesting because it allows one to study frictionless economies at all, not because it offers a different class of solutions for a given specification of monetary frictions.

The analogy between the fiscal theory and stock valuation theory brings bad empirical news. Although stock prices typically move as we expect them to when there is earnings or discount rate news, they also fluctuate a great deal in ways that are hard to explain by independent news about future earnings or discount rates. 
Similarly, we may expect that many pieces of news will move the price level in the right way, as shown by Sargent's (1986) analysis of the end of hyperinflations and Burnside, Eichenbaum, and Rebelo (1998). However, we may also expect that much short-term fluctuation in prices and exchange rates, and questions such as the exact timing of devaluations, will be just as difficult to explain based on obvious news about surpluses or discount rates as are stock prices. 


\section{References}

Aiyagari, S. Rao and Mark Gertler, 1985, "The Backing of Government Bonds and Monetarism," Journal of Monetary Economics 16, 19-44.

Bohn, Henning, 1999, "Comment," in Olivier Blanchard and Julio J. Rotemberg, eds. NBER Macroeconomics Annual 1998, 384-389.

Buiter, Willem H. 1998, "The Young Person's Guide to Neutrality, Price Level Indeterminacy, Interest Rate Pegs, and Fiscal Theories of the Price Level," NBER Working Paper 6396

Buiter, Willem H. 1999, "The Fallacy of the Fiscal Theory of the Price Level" Manuscript, University of Cambridge

Burnside, Craig, Martin Eichenbaum and Sergio Rebelo, 1998, Prospective Deficits and the Asian Currency Crisis," NBER Working Paper 6758

Canzoneri, Matthew B., Robert E. Cumby, Behzad T. Diba, 1998, "Is the price level determined by the needs of fiscal solvency?" Working paper, Georgetown University.

Cochrane, John H., 1999a, "A Frictionless View of U.S. Inflation," in Ben S. Bernanke and Julio J. Rotemberg, eds., NBER Macroeconomics Annual, Cambridge MA: MIT press, 323-384.

Cochrane, John H., 1999b, "Long Term Debt and Optimal Policy in the Fiscal Theory of the Price Level," Manuscript, University of Chicago.

Daniel, Betty C., 1999, "A Fiscal Theory of Currency Crises," Manuscript, The University at Albany

Dotsey, Michael, 1996, "Some Not-so Unpleasant Monetarist Arithmetic" Federal Reserve Bank of Richmond Economic Quarterly 82, 73-91.

Duffie, Darrell, 1992, Dynamic Asset Pricing Theory, Princeton: Princeton University Press.

Dupor, William, 1999, "Exchange Rates and the Fiscal Theory of the Price Level," Forthcoming, Journal of Monetary Economics.

Fisher, Irving, 1911a, The Purchasing Power of Money, MacMillan

Fisher, Irving, 1911b, "The Equation of Exchange 1896-1010," American Economic Review 1, 296-305.

Friedman, Milton, 1948, "A Monetary and Fiscal Framework for Economic Stability," The American Economic Review 38, 245-264. 
Friedman, Benjamin M., 1999 "The Future of Monetary Policy: The Central Bank as an Army With Only a Signal Corps?" NBER Working paper 7420.

Hansen, Lars Peter and Scott F. Richard, 1987, "The Role of Conditioning Information in Deducing Testable implications of Asset Pricing Models," Econometrica 55, 587-613.

Kaulla, Rudolph, (1934) Grundlagen des Geldwerts. Stuttgart 1920. Passage translated in German Monetary Theory: 1905-1933, Howard S. Ellis, Cambridge MA: Harvard University Press 1934.

Kocherlakota, Narayana and Christopher Phelan, 1999, "Explaining the Fiscal Theory of the Price Level," Working paper, Federal Reserve Bank of Minneapolis.

Leeper, Eric, 1991, "Equilibria under 'Active' and 'Passive' Monetary and Fiscal Policies," Journal of Monetary Economics 27, 129-47.

Leeper, Eric, 1995, "Equilibria Under 'Active' and 'Passive' Monetary Policies," Journal of Monetary Economics 27, 129-147.

Lerner, Abba P, 1947, "Money as a Creature of the State," Proceedings of the American Economic Association 37, 312-317.

Lucas, Robert E., Jr., 1980, "Equilibrium in a Pure Currency Economy," Economic Inquiry 18, 203-20.

Lucas, Robert E. Jr, 1982, "Interest Rates and Currency Prices in a Two-Country World," Journal of Monetary Economics 10 335-59.

Lucas, Robert E., Jr., 1984, "Money in a Theory of Finance," Carnegie-Rochester Conference Series on Public Policy 21, 9-45.

Lucas, Robert E., Jr. 1996, "Nobel Lecture: Money Neutrality," Journal of Political Economy 104, 661-680.

Lucas, Robert E., Jr. and Nancy L. Stokey, 1983, "Optimal Fiscal and Monetary Policy in an Economy without Capital," Journal of Monetary Economics 12, 55-93.

Lucas, Robert E. Jr., and Nancy L. Stokey, 1987, "Money and Interest in a Cashin-Advance Economy" Econometrica 55, 491-513.

McCallum, Bennett T, 1998, "Indeterminacy, Bubbles, and the Fiscal Theory of Price Level Determination," NBER Working Paper No. W6456.

Richards, Heidi Willmann, 1995, "Daylight Overdraft Fees and the Federal Reserve's Payment System Risk Policy," Federal Reserve Bulletin December 1, 1065-1077.

Sargent, Thomas J., 1986, Rational Expectations and Inflation, New York: Harper \& Row. 
Sargent, Thomas J., 1997, Dynamic Macroeconomic Theory Cambridge: Harvard University Press

Sargent, Thomas J., and Neil Wallace, 1981, "Some Unpleasant Monetarist Arithmetic" Federal Reserve Bank of Minneapolis Quarterly Review Fall 1981 (Reprinted in Sargent 1986).

Sargent, Thomas J. and Francois R. Velde, 1995, "Macroeconomic Features of the French Revolution," Journal of Political Economy 103, 474-518.

Sims, Christopher A., 1994, "A Simple Model for the Determination of the Price Level and the Interaction of Monetary and Fiscal Policy," Economic Theory 4, 381-399.

Sims, Christopher A., 1997, "Fiscal Foundations of Price Stability in Open Economies," Working Paper, Yale University.

Starr, Ross M., 1974, "The Price of Money in a Pure Exchange Monetary Economy with Taxation," Econometrica 42, 45-54.

Woodford, Michael, 1995, "Price Level Determinacy Without Control of a Monetary Aggregate," Carnegie-Rochester Conference Series on Public Policy 43, 1-46.

Woodford, Michael, 1996, "Control of the Public Debt: A Requirement for Price Stability?" NBER Working Paper 5684.

Woodford, Michael, 1998a, "Doing Without Money: Controlling Inflation in a PostMonetary World," Review of Economic Dynamics 1, 173-219.

Woodford, Michael, 1998b, "Public Debt and the Price Level," Manuscript, Princeton University.

Woodford, Michael, 1999, "Comment," in Olivier Blanchard and Julio J. Rotemberg, eds. NBER Macroeconomics Annual 1998, 390-419. 